\title{
UNA PROPUESTA METODOLÓGICA PARA UNA APROXIMACIÓN A LAS HISTORIAS DE VIDA DE LOS ARTISTAS.
}

\author{
Herramientas para una crítica de arte
}

\author{
Ilvar Josue Carantón Sánchez \\ Lo que hace que una biografía merezca ser leída y escrita son los accidentes. La intersección \\ de historias causales cruzadas que producen eventos no predecibles
}

\section{Arthur Danto}

Contar una biografía o una historia de vida se dificulta, en especial, si lo que se busca es trascender más allá del hecho cronológico o de la simple trascripción de información y de datos. Justificar una actitud diferente o una propuesta contraria a la tradicional de asumir dicha tarea, genera la necesidad de buscar referentes escritos que permitan darle peso conceptual y teórico a la propuesta, hecho que a su vez nos ubica en las antípodas de los trabajos biográficos en la historia del arte.

Si bien es cierto que desde la Grecia antigua las biografías han sido un recurso para la conservación de la memoria, y fueron ellos quienes a partir de los logógrafos de Asia Menor dieron nacimiento a la historiografía griega, no se debe olvidar que la palabra historia deriva de un verbo que significa explorar, descubrir, y que la primitiva historiografía griega era una exposición de descubrimientos. Por tanto lo que se registra busca señalar las causas de los acontecimientos y a partir de ello encontrar un sentido profundo a lo ya conocido, tarea que en muchas ocasiones debe realizar cada lector.

En este trayecto de la biografías es obligado el paso por Giorgio Vasari y su libro "Vidas de los más excelentes arquitectos, pintores y escultores italianos", en la cual se hace una mirada a la vida e intimidad de los artistas y desde donde se desprenden detalles que permiten tener otra visión de los hombres que ejecutaron las obras que hoy forman parte de la historia del arte.

Pensar una investigación que desde lo regional de cuenta de una manera distinta de hacer una historia de vida nos remite a pensar que lo que sigue estando al centro es el problema del saber, que implica instancias discursivas y no discursivas, discursos e instituciones en un periodo dado de la historia y que al mismo tiempo nos funda como sujetos. la existencia de estas propuestas investigativas nos permite comprobar un campo abierto a la problematización del nexo existente entre saber y poder. Ahora bien, una vez hecha esta sucinta revisión, podemos comprobar tanto la relevancia como la novedad del texto que tenemos ocasión de reseñar. 
Para MaurizioLazzarato la relación entre resistencia y creación es el último límite que el pensamiento de Foucault había pretendido franquear. Es en el interior de las relaciones estratégicas y de la voluntad de los sujetos virtualmente libres de "dirigir la conducta de los otros", donde se pueden encontrar las fuerzas que resisten y que crean. Lo que resiste al poder, a la fijación de las relaciones estratégicas en relaciones de dominación, a la reducción de los espacios de libertad en el deseo de dirigir las conductas de los otros, hay que buscarlo en el interior de esta dinámica estratégica. Es en este sentido que la vida y lo viviente deviene así la "materia ética" que resiste y crea a la vez nuevas formas de vida.

En una entrevista a Foucault de 1984, un año antes de su muerte, se le plantea una cuestión acerca de la definición de la relación entre resistencia y creación:

"-Es sólo en términos de negación que hemos conceptualizado la resistencia. No obstante, tal y como usted la comprende, la resistencia no es únicamente una negación: es proceso de creación. Crear y recrear, transformar la situación, participar activamente en el proceso, eso es resistir.

Sí, es así como yo definiría las cosas. Decir no, constituye la forma mínima de resistencia. Pero naturalmente, en ciertos momentos, es muy importante. Hay que decir no y hacer de ese no una forma de resistencia decisiva...". (Foucault, 1984)

Las relaciones consigo, las relaciones que debemos mantener con nosotros mismos, no son relaciones de identidad, "deben ser más bien relaciones de diferenciación, de creación, de innovación. "Por ello es pertinente proponer otras formas de acceder y de construir historias de vida o biografías sobre los artistas en Colombia, para que sus formas de pensamiento, reflexión y resistencia, permitan pensar el vuelco del biopoder en una biopolítica, el "arte de gobernar" en producción y gobierno de nuevas formas de vida. En establecer una distinción conceptual y política entre biopoder y biopolítica y la perentoria consolidación de un pensamiento crítico emergido desde la periferia que permitan dar una nueva clave de interpretación al modo de producción de los sujetos y recuperar esas memorias que desaparecen en las historias oficializadas y asépticas sobre el arte y sus protagonistas.

En Antioquia una primera pesquisa permitió a encontrar un texto de 1976 escrito por el artista Félix Ángel, donde se da cuenta de los artistas que trabajaban en esa época en Medellín y a los que su obra, les era considerada "seria", circunstancia que les daba el carácter de profesionales. En la introducción del libro Ángel nos dice:

"Es una oportunidad para que el público conozca a sus artistas en forma más íntegra; para que aprecien los juicios que dan esos artistas sobre su propia obra y los confronten con los que han elaborado otras personas; para que valoren las implicaciones que esas obras tienen con el medio - si es que la tienen -, y para que sea posible formarse una idea más acertada sobre los alcances de sus trabajos, desmitificando y destruyendo muchas ideas erróneas sobre los artistas antioqueños"(Ángel, 1976, p .5). 
Entre los artistas entrevistados para este libro estaban Rodrigo Callejas, John Castles, Oscar Jaramillo, Álvaro Marín, Dora Ramírez, Juan Camilo Uribe, Francisco Valderrama, Aníbal Vallejo y Marta Elena Vélez, a cada uno de ellos se le hizo una reseña biográfica, la publicación de algunos de los comentarios de catálogos de exposiciones individuales y luego una entrevista, la cual fue realizada por FelixÁngelen ella se daba cuenta de las reflexiones que en torno a la obra y vida hacía cada uno de artistas. Este documento permitió tener un acercamiento más profundo a las reflexiones de los artistas y en especial a las del pintor y ceramista RodrigoCallejas y tomar algunas de sus apreciaciones, para darle un enfoque diferente a la construcción de las historias de vida.

La entrevista que le realiza Ángel está planteada como una serie de preguntas que se van realimentando a medida que surgen las respuestas. Temas como el viaje a los Estados Unidos y el estudio de la cerámica son la constante, el regreso a Colombia y una mirada a sus artistas, las influencias y la pintura. Y finalmente una mirada interior.

"Félix Ángel: El sueño, los recuerdos, tu mundo íntimo, intervienen en tus cuadros de qué manera... ¿¿De manera poética $\neg$ ?

Rodrigo Callejas: Yo diría que de manera documental, y más en el sentido de recuerdo que de sueño" (Ángel,1976, p.34).

Esta afirmación brindó la oportunidad de elaborar una propuesta que se saliera de las pautas establecidas para estos casos, y abrió un panorama más amplio para hacer uso de los recuerdos y la memoria de los artistas, así que se continuó con las pesquisas y andanzas entre biografías y relatos.

En este recorrido se llegó a los pocos documentos publicados en Antioquia y entre ellos, los dos libros observados y analizados fueron los realizados sobre Justo Arosemena y EthelGuilmour, pero el primero por su esquema y modelo no fue de interés ni de motivación, y no llenó las expectativas por las siguientes circunstancias:

El texto de presentación del libro de Justo Arosemena que hace Leonel Estrada no deja de ser una mirada amistosa y evocativa, frases como "Arosemena fue indetenible, incansable en su carrera. Paralelamente le vimos como fotógrafo creativo y publicista de ideas originales. Enseñó y compartió generosamente su taller con buscadores de arte. Su talento y alegría de vivir se sintieron siempre a su alrededor. Fue pródigo hasta la saciedad"; este tipo de comentarios no permiten que se haga una mirada crítica sobre la obra de un artista ni se tenga una reflexión sobre sus intereses plásticos.

Los análisis sobre su obra escritos por el profesor Carlos Arturo Fernández y por Darío Ruíz son complejos y profundos, pero tan sólo dan cuenta de la mirada que se hace desde el exterior y en retrospectiva, circunstancia que no ofrece elementos para construir una visión desde el propio artista ni de sus verdaderos motivos frente a la obra. Es la mirada desde el afuera. Y muchas veces solo es una prosopografía o una mirada después de muertos. Es la ausencia del reconocimiento y del escucharlos en vida. Es perder, quizás para siempre las reflexiones de un 
artista que aportó sensiblemente al desarrollo del arte antioqueño; es la memoria olvidada. En estos escritos son la historia del arte, las referencias, los paralelos, los escritores y las interpretaciones quienes hablan por el artista, pero el artista no está. Y las historias de vida no son las obras.

El segundo trabajo, fue el realizado por Imelda Ramírez, sobre EthelGilmour fue una visita que da cuenta de la cotidianidad de la artista, y de los espacios de su casa, no obstante lo interesante del formato y el texto, permitió darse cuenta, sobre qué era lo que no quería hacer, porque los objetivos si bien eran parecidos, podrían caer en una repetición del formato y modelo usado, así buscando el apoyo en la herramienta de la visita al taller y casa del artista, se debería buscar otro camino, diferente al que se refiere el profesor Carlos Arturo Fernández, cuando afirma que este trabajo es "la esencial identificación entre la obra y la vida del artista o, si se prefiere, entre su trabajo artístico y su morar" .El texto en cuestión se llama: "Visita. La obra de EthelGilmour" del Fondo Editorial de la Universidad Eafit, y allí se da una relación entre texto-obra-contexto, construyéndose una hipertextualidad entre objeto y sujeto.

La formación en el mundo del arte permite tener claro que sea de vital importancia las opiniones y apreciaciones de los artistas, los encuentros con maestros y sus enseñanzas en sus talleres y fuera de las aulas de clase, generan una visión diferente del complejo y especial mundo interior del artista. Esto a su vez, se convierte en una necesidad sentida, y es el deseo de poder ampliar el círculo de personas que tengan acceso a esos saberes, para que no se queden en el conocimiento de unos pocos que tienen la fortuna de aprender y establecer un diálogo personal con ellos, sino que esas experiencias puedan ser compartidas y transmitidas, para que la memoria colectiva siga siendo alimentada y revitalizada.

Con el deseo de no caer en los lugares comunes, ni en las repeticiones, ni en los profundos y hoy cuestionados fondos de los discursos teóricos, el deambular por biografías, autobiografías, memorias, estudios monográficos, revisiones de comentarios de catálogos, de reseñas de prensa, de revistas y demás, permitió que por casualidad y por azar se llegara a las memorias del gran actor italiano, MarcelloMastroianni, tituladas Sí, ya me acuerdo..., las cuales fueron filmadas en el norte de Portugal, en septiembre de 1996, mientras Mastroianni rodaba una película. El libro es una trascripción de su voz.

Lo particular de este libro es que con el tema del cine se desarrolla una especie de entrevista, no cronológica, llena de detalles y momentos determinantes e importantes para la formación actoral de Mastroianni y que por su forma aparentemente simple nos lleva a hurgar en los rincones de un personaje respetado y con grandes cosas para aportar al ejercicio de la formación actoral.

\section{NOSTALGIA DEL FUTURO}

Cuando somos pequeños, los países que no conocemos y sobre los que tanto fantaseamos nos parecen siempre más bellos y misteriosos, incluso más reales que las ciudades donde vivimos. Tal vez la profunda fascinación de viajar permanece siempre 
ligada a esta especie de perspectiva fantástica que vuelve los lugares lejanos a la vez más misteriosos y reales que los que tenemos ante nuestros ojos.

Según Proust, "los verdaderos paraísos son los paraísos perdidos". Es una frase justamente famosa. Yo me permito añadir que acaso existen paraísos más atractivos aún que los paraísos perdidos: son los que no hemos visto nunca, los lugares y las aventuras que entrevemos a los lejos; no a nuestra espalda, como los paraísos perdidos, que nos Ilenan de nostalgia, sino delante de nosotros, en un futuro que quizás un día, como en los sueños que se hacen realidad, conseguiremos alcanzar, tocar.

Quién sabe, tal vez la fascinación de viajar radique en este encanto, en esta paradójica nostalgia del futuro. Es la fuerza que nos mueve a imaginar - o a ilusionarnos con ello - que haremos un viaje y encontraremos, en una estación desconocida algo que podría cambiar nuestra vida.

Acaso uno de realmente de ser joven cuando tan sólo es capaz de añorar y amar los paraísos perdidos. (Mastroianni, 1997,30).

En este apartado del libro, Mastroianni nos da muestra de su saber y de sus gustos literarios, reflexiona sobre los recuerdos y los proyecta, en pocas líneas da cuenta de sus gustos por viajar y ser, como muchos los catalogan, un turista de lujo, inquieto y siempre a la espera de dejarse sorprender por la vida, nos dan un ejemplo de fortaleza y de sus nunca abandonados sueños, en síntesis nos revela su lado humano. Esos sueños se ligaban a lo expresado por el maestro Rodrigo Callejas, en sus respuestas para el libro de Félix Ángel y dejaban entrever la puerta por la cual se desarrolla la propuesta.

En otra parte del libro nos devela al simple comediante, como él mismo solía considerarse, el cual como una caja vacía estaba dispuesto a recibir palabras de otros y a devolverlas al público bajo los focos de una cámara o como lo hace esta vez, en forma de palabras, lo cual también encajaba perfectamente con el ejercicio de escuchar, recibir y devolver.

\section{UN DUENDE SHAKESPEARIANO}

Roberto Benigni: decir "actor" no me parece suficiente. Es un duende shakespeariano, genial. Siento por él verdadera admiración. Por su arte y por su modestia en la vida.

Hace unos meses, cuando yo estaba trabajando en el teatro y la obra tuvo éxito, me mandó un telegrama (escrito en toscano): "iDios bendito! iTú deberías ser actor!"

Querido Roberto, te mando un gran saludo. (Mastroianni,1977, 45)

Estos ejemplos cortos y reflexivos que permiten, con toda claridad, ver la profunda calidad humana y la inteligencia de un ser, forman parte de muchos otros que hicieron que se decidiera 
por este formato para realizar la investigación y la construcción de las historias de vida del maestro Rodrigo Callejas.

Este detalle se ligaba con la idea de realizar un trabajo desde la microhistoria, propuesta por Carlo Ginzburg, y que se ajustaba a las condiciones y a la idea de hacer un aporte académico para la historia del arte colombiano. Esta opción, como una especie de rompecabezas, encaja al ejercicio del saber humano en forma tentativa y provisional en la que operamos y optamos por lo que pensamos que es lo mejor.

\section{LA MICROHISTORIA}

Haciendo un uso metafórico del cómo escribir una historia,vale la pena notar que la metáfora (visual o no) se ha convertido en algo generalizado en este mundo tecnológico en que vivimos, y esa designación de algo a través de otra cosa, mediante un ejercicio de similitud y sustitución haciendo uso de la Microhistoria nos podría llevar, utilizando la metáfora del mosaico, a una reconstrucción de piezas o elementos que de forma indirecta ayuden a construir una memoria, que permita ser leída desde particularidades, muchas veces inconexas, pero que amplían el marco de percepción y análisis en torno al complejo desarrollo implícito en una obra.

Para ir más lejos y no quedarse cortos, es necesario ver que ciertos procesos historiográficos llevan a una "depuración", manipulada en la información, la cual en su asepsia elimina detalles, muchas veces intrascendentes, que para un lector entrelíneas aportan más que lo comúnmente dicho. En este caso se puede usar el ejemplo del restaurador de una obra de arte, el cual se da a la tarea de lavar la superficie, retirar el barniz y eliminar el exceso de pintura para devolver al espectador el cuadro original, el mismo que tuvo el artista ante sus ojos.

No se debe olvidar que los presupuestos conceptuales de cada individuo, también determinan los resultados y que como ésta es una opción más, frecuentemente utilizada desde la Historia del arte que desde las metodologías de las Ciencias Humanas, los resultados no se pueden medir bajo los criterios de una disciplina común.

A nivel epistemológico las posibilidades de acceder al conocimiento en el ámbito de la disciplina histórica, tiene que ver con problemas como la realidad, la verdad, la documentación, en el fondo el proceso de investigación, y allí la Microhistoria, corriente en la que la investigación son fragmentos y sus contornos no necesariamente son precisos e incluso, podría llegar a realizarse sin referentes ciertos seguros; no obstante, lo evanescente que podría resultar, la historia, tal y como la concibe Carlo Ginzburg, sería una disciplina que funcionaría por fragmentos: una averiguación, una pesquisa que pone en relación conjetural vestigios, huellas, indicios.

Si bien este va a ser el modus operandi, se podría decir que el fragmento es un corte de algo que se ha roto, fracción accidental y circunstancial, algo fortuito que se va recogiendo en forma tentativa para ir llenando vacíos, buscando conocer el conjunto al cual pertenece y el camino a recorrer, es ir relacionando estos fragmentos entre sí, aludiendo a un proceso inductivo-abductivo. 
Las investigaciones microhistóricas han examinado temas de reconocida importancia, tanto como temas ignorados o relegados a ámbitos considerados inferiores como la historia local, han afrontado la cuestión de la comparación como una anomalía, cada configuración social es producto de la interacción de innumerables estrategias y posiciones individuales, son una trama que sólo la observación y el diálogo cercano permiten reconstruir. La relación entre esta dimensión microscópica y la dimensión contextual se ha convertido en el principio organizador de la narración, esta heterogeneidad constituye su máxima dificultad y su máxima riqueza potencial.

No obstante su importancia no se cuenta con ningún texto teórico que defina el paradigma bajo el cual se han amparado las investigaciones microhistóricas, todas ellas muy distintas y de desigual valor. La microhistoria italiana, como ejemplo paradigmático y central de esta corriente, no sigue una trayectoria similar a la que siguió la Escuela de Annales. Parte del éxito se debe a un factor azaroso que es el de la cualidad personal de algunos microhistoriadores que son excelentes escritores, y sus obras son ejemplo de sabiduría narrativa.

Para profundizar un poco más de esta Escuela es interesante conocer un poco de su historia:

El primero en utilizar la palabra "microhistoria" fue el estudioso americano George R. Stewart, en 1959, profesor de la Universidad de Berkeley, quien en una conferencia sostuvo que para interpretar un texto literario es necesario, en primer lugar, descifrar las referencias ambientales que contiene. Esta pasión por el detalle microscópico inspiró su libro Pickett'sCharge. A Microhistory of the final Attack at Gettysburg, July 3, 1863 (1959), donde analiza minuciosamente la batalla decisiva de la guerra civil americana.

En 1968 el mejicano Luís González y González insertó la palabra "microhistoria" en el subtítulo de su libro Pueblo en vilo, microhistoria de San José de Gracia. En este libro se investigan las transformaciones producidas a lo largo de cuatro siglos en un pueblo minúsculo, siendo microhistoria aquí sinónimo de historia local, escrita desde una óptica cualitativa y no cuantitativa. El éxito del libro le animó a teorizar sobre la nueva corriente en dos ensayos El arte de la microhistoria, y Teoría de la microhistoria incluidas en dos colecciones llamadas Invitación a la microhistoria (1973) y Nueva invitación a la microhistoria (1982).

Aunque el nombre en sí emanó de la serie de publicaciones italianas titulada Microstoria, e incluso, se podría hablar de "microanálisis", la aproximación analítica al respecto nos la ofreció Giovanni Levi, quien fue el primero en hacer una aproximación teórica de aquello que llamamos microhistoria; en el capítulo del libro Nuevas perspectivas en historia, en donde pretende lanzar una mirada global a la dirección de la microhistoria italiana señala que esta corriente es por esencia una práctica historiográfica.

Levi intenta caracterizar la corriente historiográfica de la microhistoria y enumera un total de siete rasgos:

1. La reducción de escala.

2- El debate sobre la racionalidad.

7|Page Vol1, No 2/2013 ABCResearch Alert 
3- El pequeño indicio como paradigma científico.

4- El papel de lo particular.

5- La atención a la recepción y al relato.

6- Una definición específica del contexto.

7- Rechazo al relativismo.

James Amelang resume la microhistoria italiana en seis elementos centrales o recurrentes:

1- La reducción de escala.

2- La preferencia por lo singular o por lo extraordinario.

3- El estudio de la historia social centrada en las clases populares.

4- El análisis basado en el paradigma indiciario.

5- Una aproximación transparente al conocimiento histórico.

6- Su predilección por la forma narrativa.

De igual modo la necesidad constructiva de subjetividades, no permite mirar el análisis que hace Michael Hardt en su texto "la sociedad mundial del control", con respecto al tema:

"La falta progresiva de distinción entre el adentro y el afuera en el paso de la sociedad disciplinaria a la sociedad de control, tiene implicaciones importantes para la forma de la producción social de la subjetividad. Una de las tesis centrales y más comunes en los análisis institucionales de la teoría social moderna es que la subjetividad no está dada de entrada y originalmente, se forma, en cierto grado al menos, en el campo de las fuerzas sociales. Las subjetividades que interactúan sobre el plano social son ellas mismas sustancialmente creadas por la sociedad. En ese sentido, esos análisis institucionales han vaciado de su contenido cualquier noción de subjetividad presocial; para en su lugar arraigar la producción de la subjetividad en el funcionamiento de las instituciones sociales mayores, tales como la prisión, la familia, la fábrica y la escuela.

Debemos subrayar dos aspectos de ese proceso de producción. Primero, la subjetividad no está considerada como algo fijo o dado. Es un proceso constante de generación. Las prácticas materiales presentadas para el sujeto en el contexto de la institución (sea que se trate de arrodillarse para orar o de cambiar cientos de pañales) forman procesos de producción de su propia subjetividad. El sujeto es activo, engendrado de manera reflexiva por las vías de sus propios actos. Segundo, las instituciones proporcionan sobre todo un lugar discreto (el hogar, la capilla, el salón de clase, el taller) donde se monta la producción de la subjetividad. Las diversas instituciones de la sociedad moderna deberían ser vistas como un archipiélago de fábricas de subjetividad. En el transcurso de una vida, un 
individuo atraviesa linealmente por dentro y por fuera de esas diversas instituciones (de la escuela al cuartel y a la fábrica) y es formado por ellas. Cada institución tiene sus propias reglas y lógicas de subjetivación."(Hardt, 1996)

Dentro de esta línea conceptual también es necesario revisar y hacer un análisis al paradigma indiciario, te que encontramos desarrollado y expresado por Carlo Ginzburg en el libro El signo de los tres, Dupin, Holmes y Peirce, editado por Umberto Eco y por Thomas A. Sebeok, en el capítulo IV, titulado Morelli, Freud y Sherlock Holmes: indicios y método científico, Ginzburg parte su recorrido desde el llamado método Morelli, médico italiano quien estableció un método para identificar la autenticidad de las obras de arte basado en los detalles menores, especialmente en los menos significativos del estilo típico de la escuela del pintor, como eran los lóbulos de las orejas, las uñas, la forma de los dedos de las manos y de los pies. El modelo no abordaba el problema a nivel estético sino a un nivel más básico, cercano a la filología.

Según el texto de Ginzburg, Freud descubre el documento que había sido publicado en 1874, y llega a la conclusión de que el psicoanálisis acostumbra a deducir de rasgos poco estimados o inobservados del residuo de la observación, cosas secretas o encubiertas y vincula la intimidad individual con elementos sustraídos al control de la conciencia.

En Morelli, Holmes y Freud, a partir de unos detalles minúsculos, Ginzburg encuentra la clave para acceder a una realidad más profunda, inaccesible por otros métodos. Para Freud son síntomas, para Holmes pistas o indicios y para Morelli rasgos pictóricos. Este enfoque en la interpretación de los indicios llegó a tener una gran influencia en el campo de las ciencias humanas.

Según Freud un método interpretativo se puede basar en considerar detalles marginales o irrelevantes como indicios reveladores. Este método donde los detalles considerados como triviales y carentes de importancia, son los que proporcionan la clave para acceder a los productos más elevados del espíritu humano. Para Morelli, esos detalles marginales resultaban reveladores porque en ellos la subordinación del artista a las tradiciones culturales desaparecía y daba paso a una manifestación puramente individual, por lo que los detalles se repetían de modo "casi inconsciente, por la fuerza de la costumbre".

La recopilación de esos "pequeños discernimientos" como los llamó Winckelmann, fue la base de las nuevas formulaciones de antiguos saberes realizadas durante los siglos dieciocho y diecinueve, pues ese acceso a una experiencia específica que tuvo el público se dio a través de los libros y en especial fue por las obras de ficción, que el paradigma indiciario logró un éxito inesperado.

La idea de Morelli fue rastrear, en el seno de un sistema de signos culturalmente determinado, las convenciones de la pintura. Signos que se producían de manera involuntaria, y que en sus minúsculos detalles utilizados sin intención, le permitieron a Morelli localizar el más certero signo de la individualidad del artista. Estos principios metodológicos coincidieron con la tendencia del poder estatal a extender sobre la sociedad una espesa red de controles, y una vez más el método utilizado implicaba la atribución de identidad a través de características que era triviales y fuera del control consciente. 
Para la mayoría de los microhistoriadores, la microhistoria es un intento saludable de desembarazarse de las coerciones cognoscitivas y las ineficacias explicativas que la tradición política ha impuesto. Nace pues de un hecho intelectual: la crisis del marxismo, es una respuesta en el ámbito historiográfico a una constatación cultural-civilizadora que acontece entre finales de los setenta y los ochenta: la crisis de la razón.

Identificada con la postmodernidad, la microhistoria permite compartir la certidumbre de una quiebra de paradigmas, los cuales tradicionalmente se han sostenido para explicar desde lo general una realidad que siempre es local y particular, y es desde allí, de donde los microhistoriadores tratan de formular algún nuevo "paradigma" bajo el cual puedan integrar sus investigaciones parciales y dejar de asumir una concepción positivista en el sentido de asumir la narratividad en el discurso histórico.

\section{LOS OTROS SABERES}

Otro de los soportes conceptuales que se pueden aplicar a este tipo de investigaciones hace referencia a Mijail Bajtín, fundador de la dialógica, concepción que se opone a lo monológico del lenguaje, que separa a las expresiones del contexto dialógico en el cual ocurren. Para Bajtín y según su dialógica, cualquier expresión, por completa o autónoma que parezca, no es otra cosa que un momento de un diálogo, un fragmento en el proceso continuo de la comunicación verbal o intertextual.

Si pensamos cómo es el funcionamiento de la entrevista desde el punto de vista de la situación comunicativa y sus participantes, la perspectiva de Mijaíl Bajtín resulta sumamente útil. Este teórico ruso, cuyos trabajos han tenido una influencia perdurable en la lingüística, la crítica literaria y otras disciplinas, ha desarrollado una reflexión tan profunda como abarcadora en torno de la enunciación y de su naturaleza interactiva, hasta el punto que su teoría suele denominarse «dialogismo».

Para Bajtín, toda enunciación es dialógica, es decir, supone siempre un interlocutor (éste puede estar presente, ausente, fantaseado), y por lo tanto, el atributo principal de todo enunciado es su carácter de destinado, modulado por la "presencia» del otro (el destinatario), en la medida en que argumenta para persuadirlo, le responde por anticipado, se adelanta a sus objeciones («tal como yo me las imagino») a partir de una hipótesis sobre su capacidad de comprensión. El destinatario es entonces una figura imaginaria, una idea que tenemos de cómo podrá ser nuestro «Lector Modelo»; sin embargo, está inscrito en el texto o en la conversación, en su lenguaje, sus giros, sus recorridos.

La idea de que el destinatario está presente en el enunciado aun antes de que pueda emitir cualquier respuesta, e inclusive independientemente de ella, sugiere un protagonismo conjunto de los partícipes de la comunicación. Siguiendo esta línea, la recepción puede ser vista como un proceso activo y simultáneo, donde si bien la secuencia lógica es que «uno habla y el otro escucha», para luego invertir los términos, en realidad ocurre que todos «hablan» todo el tiempo (ese continuo asociativo en que uno imagina, recuerda, piensa, evalúa mientras alguien dice). 
Tal apreciación, válida aun para la relación desigual que sostenemos con los medios de comunicación, donde no tenemos posibilidad de "emitir» nuestra respuesta, es muy relevante en el caso de la entrevista, en la cual el diálogo se construye precisamente en esa mutua adecuación de hablar no solamente para sino por otro.(Arfuch,1995)

A su vez Bajtín empleó la metáfora de la polifonía, noción que originalmente hace referencia a una composición musical en la cual se superponen las partituras, para oponer y caracterizar dos formas de literatura, una la dogmática, en la que domina la voz del autor y la polifónica o carnavalesca, de origen popular, en la que existen varios personajes que se presentan a sí mismos y donde el sentido global de la obra lo da la confrontación de los personajes.

Según Carlos Reynoso, en la introducción al libro El surgimiento de la antropología posmoderna, en la que hace un examen a la antropología posmoderna, se podrían distinguir tres grandes líneas o corrientes, las cuales son aplicables a la Historia del Arte, este tríptico sería el siguiente:

Una corriente que podría ser llamada "meta-etnográfica" o "meta-antropológica", la cual se preocupa por analizar críticamente los recursos teóricos y "autoritarios" de la etnografía convencional y de tipificar nuevas alternativas de escritura etnográfica. Caracterizada como "antropología de la antropología", su objeto de estudio no es ya la cultura etnográfica, sino la etnografía como género literario por un lado y el antropólogo como escritor por el otro.

La segunda caracterizada por ser una "antropología experimental", donde se redefinen las prácticas, o por lo menos las formas en que la praxis del trabajo de campo quedan plasmadas en las monografías etnográficas. Aquí se ubica una de las corrientes más claramente definidas, "la etnografía Dialógica", elaborada por el antropólogo Dennis Tedlock de la Universidad de Buffalo en Nueva York.

La tercera no se interesa ni por el análisis pormenorizado de la escritura antropológica tradicional ni por la renovación de la literatura etnográfica; su espíritu es disolvente, proclamando la caducidad de determinadas formas de escribir, y la crisis de ciencia en general. Esta Vanguardia, para usar un término artístico, está representada por Stephen Tyler y Michael Taussig, donde el primero propone una epistemología irracionalista que reformula todo el proyecto científico desde la raíz, en términos todavía pragmáticos; y el segundo hizo estallar el género y la "autoridad etnográfica" mediante el uso simbólico del montaje y el collage.

El tríptico podría situarse en una línea que involucra primero la situación de la escritura etnográfica como problema, en nuestro caso la histórica-etnográfica, luego la práctica de nuevas escrituras o Microhistorias, con trascripciones recreadas en forma literaria y por último el estallido de los géneros literarios académicos a través de la perdida de la forma en Taussig y de la escritura en Tyler, para el caso de la historia del arte podría ser aplicable en forma similar y permite construir un enfoque amplio emanado de la experiencia etnografía y de antemano multiplica las posibilidades interpretativas; aunque entre las tres líneas existe cierta superposición, el ordenamiento realizado por Reynoso facilita la visión panorámica. 
Optar por la perspectiva formal de Taussig y no por la escritural de Tyler; tiene dos circunstancias determinantes, en primer lugar a que el desarrollo de su trabajo y su obra más significativa, Chamanismo, colonialismo y el hombre salvaje. Un estudio sobre el terror y la curación, se realizó en Colombia entre los años 1969 y 1985 y en segundo lugar, porque su propuesta emana de una incursión en varios terrenos como la historia, la antropología, la medicina, la mitología y la magia, sólo por mencionar las que tienen nombre, según sus propias palabras, y dejar el resto en el punto en que los textos y las obras se expresan por sí mismos y en la misteriosa dialéctica del yo y el Otro.

Por fuera de todo esto, dice Reynoso, existe un marco que se podría llamar postmodernismo antropológico genérico, el cual no se alimenta de los desarrollos específicamente disciplinares cuya dinámica ya está establecida, sino que abreva directamente en el pensamiento posmoderno no disciplinar, siguiendo algunas líneas como son la crisis de metarrelatos, el colapso de la razón, la deconstrucción o el fin de la historia.

El modelo usado por el postmodernismo antropológico nos ayuda a plantear ciertas preguntas en torno a la Historia del arte: ¿Somos partidarios de una concepción interpretativa de la disciplina? ¿Nos ha faltado conciencia en los modos de representación y de experimentar con ellos? ¿Podría incluirse la historia del arte en el género de la ficción? ¿Permite el modelo usado por la etnografía ser usado para la historia del arte, especialmente en la aplicación de la polifonía, la dialógica y la autoría dispersa? Estas respuestas se pueden intentar dar en las conclusiones, luego del análisis de los resultados de las propuestas.

En 1979, Dennis Tedlock, principal exponente de la antropología dialógica, publica el artículo "La tradición analógica y el surgimiento de una antropología dialógica", donde dice que si la antropología sociocultural estuviera basada solamente en la observación silenciosa, no habría nada que la distinguiera de las ciencias naturales, más aún, cuando el campo del estudio cultural se basa en el ámbito de la intersubjetividad humana, donde el diálogo antropológico crea una comprensión de las diferencias que existen entre quienes participan del diálogo al dar comienzo a una conversación. Pero también afirma que cuando se prepara el texto sobre la experiencia, para su presentación, esta dimensión dialógica se pierde en beneficio de la tradición analógica.

Como lo dominante en la tradición analógica es el monólogo, se pierde el diálogo y se disfraza de diálogo, haciendo que quien habla se pierda en el rol actoral de quien escribe. En el teatro, un monólogo es un diálogo en el que un orador tiene interlocutores que están ausentes o son imaginarios y cuando se escriben historias difícilmente se deja que los demás digan algo, y se citan a otros para que hablen por ellos. Cuando se habla de diálogo en una novela o en una obra de teatro, no sólo se habla de dos personas, pues dia en diálogo no significa "dos", significa "a través".

El diálogo es posmoderno en su esencia, en tanto se esté desarrollando. No es posible ninguna metanarrativa que lo abarque, y si lo hace, llegando a un punto de completo acuerdo, ya no dialogan. Todo lo que se dialoga sucedió en ocasiones anteriores, incluyendo ocasiones en las que no estábamos copresentes, por tanto no se puede afirmar que lo que digamos en ese diálogo sea 
original, en el sentido de que nunca se ha dicho antes, lo que si tendrá, serán matices únicos de esa ocasión particular. Tampoco puede haber diálogo sin que haya actos de traducción, rompiendo la copresencia, ocasionando períodos de ausencia a lo largo del diálogo.

Luego del diálogo existe el acto de construir la traducción verdadera, la cual es imposible. Re-decir dentro de una lengua, lo que Jakobson llamo "traducción intralingual", es una extensión adicional del discurso anterior, a través del presente y hacia el futuro, que a medida que se desarrolla toma algo de lo que se dijo antes, pero no todo, y puede ganar algo nuevo en la medida que pierde algo de lo viejo. Algo que se reconoce permanece y nos lleva al "texto original", es decir a la fuente; pero ya no será como era antes.

\section{METODOLOGÍA}

La propuesta al poner palabras como tema, busca ampliar la mirada de la o las respuestas, y de esta manera no es dirigida. Además si se mira que el diálogo se establece a través del otro, las palabras van surgiendo de hacer una revisión de los textos y comentarios que hayan dado cuenta de las obras y procesos y del conocimiento que se posea sobre el artista a estudiar.

La palabra como conductor de un dialogo no limita ni los recuerdos ni la posibilidad de soñar, todo lo contrario, los amplía, pues no existe la condición cronológica y de paso se respeta la memoria, los recuerdos y los sueños de quien está siendo nuestro interlocutor. Este tipo de charla abierta, a su vez, permite recomponer palabras a medida que se desarrolla.

Un modelo similar al que se está proponiendo, fue publicado en los primeros números de Artes, la revista. En los números 3 y 4 de la revista se hacen, respectivamente, doce preguntas a Germán Londoño y quince a José Ignacio Vélez, pero lejos de lo que se podría imaginar, el ejercicio, no obstante el uso de las palabras, estas se acompañaban con artículos que limitaban y determinaban la respuesta.

Como lo afirma la presentación del texto "no es en sentido estricto una entrevista sino un intento de aproximación a las motivaciones, intereses y conceptos de un artista a través de una serie de referencias culturales de amplio significado, planteadas de manera puntual". El análisis de este ejercicio permitió la construcción y el fortalecimiento de la metodología para hacer lashistorias de vida, pero sin limitar ni condicionar las respuestas.

Al artista Germán Londoño se le plantearon las siguientes preguntas:.

\section{Un libro}

\section{G.L: El signo y el sello, de Graham Hancock.}

\section{Un cuadro}

G. L: No se'. Vamos pensando... [La respuesta llega solo un mes después]. Los nenúfares, de Monet; pero aquel tríptico gigantesco del Museo de Arte Moderno de Nueva York, que parece envolver al espectador cuando llega a la salita especial donde está colocado. Me 
gustaría hacer algo que tuviera un efecto parecido en la serie Recuerdos del mar, que estoy trabajando.

\section{Una escultura}

G. L.: El torso de Dionisos, del frontón del Partenón.

4. Un edificio

G. L.: El templo de Déndera, en Egipto. Pero no por decir que conozco a Egipto, sino por lo que he leído, sobre todo del viaje de Champolion a ese templo.

5. Un objeto de la historia [EI mismo Germán Londoño insiste en que sería bueno agregar esta pregunta, que no estaba contemplada]

G. L.: El Arca de la Alianza.

6. Un artista colombiano vivo

G. L.: Edgar Negret.

7. Un artista de la historia del arte (colombiano o no)

G. L.: No digo que Praxiteles, porque eso sonaría extravagante. No respondo que Picasso, porque eso sería como decir que uno cree en Dios. No sé. Voy a pensarlo mejor.

8. Una película

G. L.: Me gusta mucho AndreiRubliov, de Tarkovski. iAhí iYa sé cuál es el pintor! AndreiRubliov, porque realizó una obra perfecta en medio de una situación difícil. De películas, recuerdo mucho una escandinava que se llama La sombra del cuervo. Bueno pero la que quiero decir es Los diez mandamientos, de Cecil B. de Mille.

9. Un museo

G. L.: Decir que el Museo Metropolitano de Nueva York, el Louvre o la Galería de los Oficios de Florencia, sería demasiado previsible. Quizá podría decir que el Museo del Oro, que me impresionó mucho cuando estaba pequeñito. Pero creo que prefiero responder aquí que el Museo del Hombre en París

10. Una ciudad

G. L.: Eso sí que está difícil porque cada lugar puede ser muchas cosas. Pero digo que Granada, en España, donde pude vivir cotidianamente La Alhambra.

11. Un país 
G. L.: No digo que Egipto, porque ese es ante todo un país mitológico. Bueno. Tíbet, aunque no he ido. Pero mejor Etiopía.

\section{Un período o un estilo artístico}

G. L.: Podría decir que Bizancio; pero eso a la mayoría de la gente le suena como una cosa vieja; claro que Bizancio no es algo viejo para mí. Pero quizá prefiero señalar ese momento en el cual todos los templos antiguos, como Delfos por ejemplo, ya están vacíos.

En este ejemplo se puede observar la complejidad a la que se ve sometido el entrevistado, con el uso del artículo UN o UNA, también se detalla el tiempo para reflexionar las respuestas y la aparición de dudas sobre las mismas respuestas. A su vez nos damos cuenta del grado de formación y de los gustos e inclinaciones estéticas del artista, no presentes de forma evidente en su obra, lo que nos amplía el panorama y la complejidad de sus trabajos.

En el otro ejemplo se realizan 15 preguntas a José Ignacio Vélez y de ellas podemos extraer:

\section{Una escultura}

Toda la escultura de Henry Moore, e inclusive su concepto de escultura, que es una búsqueda alrededor de los elementos más simples de la naturaleza, como el hueso o las piedras. Es una escultura fundamental, que parte de lo más primario. Yo creo que aquí está presente toda la escultura.

\section{Una película}

El sol del membrillo, una película española que es importante inclusive para asuntos como la didáctica de la historia del arte. No recuerdo el nombre del director, pero la idea general y el guion son del pintor Antonio López. Me gusta porque es un acercamiento a la pintura absolutamente esencial desde lo cotidiano, revelado de manera muy profunda. Aparte de que tiene todos los valores del video y del cine espontáneo, sin muchos recursos. Es pintura, cine, textos, todo involucrado en una totalidad.

\section{Un objeto de la historia}

Más que uno, muchos objetos: el ejército de guerreros de terracota de QinShiuang, el emperador chino, aproximadamente del 220 al 200 antes de Cristo. Tres mil jinetes con sus caballos, en terracota y en esas dimensiones; la altura de los jinetes oscila entre 1,75 y 1,97 $\mathrm{m}$; los caballos son de 1,50 $\mathrm{m}$ de altura y $2 \mathrm{~m}$ de largo. Una terracota hueca de ese tamaño. iCómo serían los hornos! Sólo pensar en eso me eriza. Es una de las maravillas del universo, cada uno en una posición propia, con un arreglo del pelo diferente, una manera de poner las manos siempre distinta a todas las demás.

6. Un artista vivo, en el ámbito colombiano 
Por todo, Gregorio Cuartas. Desde aquella Piedad que presentó en una Bienal y que me conmovió tanto. Por todo; porque es un verdadero maestro, un artista total, básico e interior, arquitecto sin haber estudiado arquitectura, escultor sin haber estudiado escultura, pintor, dibujante. La vida me dio el inmenso regalo de haberlo conocido y de haber congeniado muy bien con él, lo que no siempre es tan fácil.

En este ejemplo se observa al igual que en el anterior lo complejo del mundo del artista, pero aquí aparecen respuestas más complejas, que incluyen las emociones y las posiciones personales, articuladas con sensaciones y apreciaciones que emanan de su mundo interior, sin dejar de lado la precisión sobre lo que se le pregunta y sin caer en retóricas. Lo que se lee es a un ser sensible y humano que aún se sorprende con las cosas de la vida y sobre esta premisa se articularon las palabras, para dar cuenta de ello.

El modelo que se propone fue aplicado al maestro Rodrigo Callejas y estás fueron algunas de las respuestas, en encuentros en su taller de la Ceja y en su apartamento en Medellín.

\section{BLANCO}

La tela me encanta blanca, pero también me gusta agredirla, ensuciarla. Recuerdo que de niño, en mi casa, como éramos cuatro hombres y tres mujeres, los hombres siempre dormíamos en el mismo cuarto, cada uno en su cama, y mi cama estaba arrinconada contra la pared, frente a una pared blanqueada con cal, entonces ante tal tentación, sacaba el lápiz y dibujaba caras, razón por la cual me regañaban, pero me fascinaba pintar encima de la pared, era una obsesión. Nunca hubo el trauma de enfrentarme a una tela en blanco. Como me encanta dibujar la pared, aquí en mi taller tengo muchos dibujos hechos en las paredes. Pero también es una cosa cultural, pues siempre nos han dicho: "la pared y la muralla son el papel del canalla", ino ensucie las paredes! Por eso digo que soy un artista contestatario, pues he estado en contra de lo que me están imponiendo. Y esa actitud llegó incluso hasta mi periodo de formación en Chicago, cuando nos graduamos, con la capa y el birrete, todos nos bajamos los pantalones, nos volteamos he hicimos una venia, como una forma de agredir lo institucional. Nunca he estado con lo establecido.

Continúo siendo contestatario en mi obra actual, pues estoy chorreando pintura, pero ya no en telas, sino pintando los pisos de mi casa, haciendo uso de las pinturas industriales, estoy haciendo cosas que no obedecen a una forma establecida de hacer un cuadro. Veo más godos, los cuadros hechos en acrílico, que los cuadros que estoy haciendo ahora. $Y$ estoy más viejo. Es una actitud de vida, pues entre más viejo me vuelvo, me torno más rebelde más libre, me provoca hacer más lo que no se usa. Que no sé qué es, pero que sea contrario a, si se está haciendo Happening no quiero hacer happening, si se usan los videos, no quiero hacer video, sé que a lo mejor me vuelvo exitoso haciéndolos, pero, ahora como se usan tanto me da rabia.

$Y$ como hay mucho pecado sin estrenar quiero que me cuenten cuáles son, porque estoy aburrido con los establecidos y ya no sé cómo más pecar. Los establecidos son aburridores. 


\section{CONTRARIO}

Nunca he pensado que haciendo arte se oculten cosas. Lo único que he profundizado en mi pensamiento es que la pintura y el arte, como la medicina, han sido unas disciplinas que siempre han ido por delante y no sé por qué. Antes no existían los libros de arte, pero si los libros de medicina ilustrados por los artistas, a esta tarea se dedicaron Durero, Leonardo, porque hay una cosa humana y más que ocultar lo que allí se encuentra, es la libertad total. Es la libertad. Es la historia de la humanidad, que es en la historia que más creo, es donde cabemos todos, los caballeros, las prostitutas, los hijos de puta, las señoras, la religión, la ciencia; es en suma, la historia del hombre.

En ello hay algo de angustia, expresada en la forma que cada uno tiene para manifestarse. Mi hija incluso, cuando era niña me decía que yo era morboso, y no le preguntaba por qué, pues estaba viendo constantemente lo que hacía. Entonces eso se convierte en una forma pedagógica de enseñanza para ella, pues existe una libertad, ya que no hay pecado en ciertas cosas que han sido cargadas de una moral extraña, como el amor, como el sexo y como la sensualidad. Lo que si se debe mirar con cuidado son las exageraciones, pues quien las práctica se vuelve víctima de eso o se las goza, eso es responsabilidad individual. Volverse víctima es el propio castigo.

Me puedo volver víctima del sexo, o de las drogas o del tabaco o de cualquier cosa, pero los disfruto con cierta medida. Pienso que debe haber autonomía en disfrutar las cosas que uno decide, pues si te dicen, iprohibido!, es lo primero que se hace. De ahí que la prohibición es muy importante, porque entonces, ¿qué se violaría? Por eso, prohíban bastante para hacer lo contrario.

Eso lo he usado hasta con mis hijos, a mi hija en Bogotá le decía: no vas a ir al colegio, con ese frío subirse en un bus para ir al norte, no te vayas mi princesa a salirte de esas cobijas tan calientitas. Entonces ella reaccionaba y me decía, ique si voy, hacéme el desayuno que me voy a bañar!

Uno siempre quiere hacer lo contrario.

\section{VOYERISTA}

La represión es importante para saber dar las libertades. Estuve en los Estados Unidos en un campo nudista y no había nada más aburridor que ver a unos individuos boleando los senos y los genitales al aire. De esta manera se deja de ver la belleza, por ello pienso que es importante el traje, que es todo lo contrario, es lo que esconde.

Los artistas somos voyeristas, y es el ojo es el que juega, de esta forma son el ojo y la mente los que trabajan. Pero viendo todo a la vez, se vuelve muy monótono. Lo menos 
sensual es un tipo que se le desnude a una niña, de buenas a primeras, eso tan sólo le produce pánico. O Viceversa, se llega a empelotar una vieja, salgo corriendo, de miedo.

No creo que haya cosas malas, si eso significa que haya algo malo se debe a que se tienen esquemas o taras para calificar. Por ello es importante la niñez, siempre he dicho que los niños son los mejores artistas del mundo, porque pintan emocional y emotivamente sin que los hayan tarado diciéndoles cómo se hacen las cosas.

Ser un buen profesor tiene que ver con eso, dejar que el alumno sea como quiere ser él y no como usted o yo queramos. El profesor es un compañero que guía, debe ser un amigo y no un personaje anónimo que enseña cosas. Eso fue lo que tuve con Rafael Saénz, un romántico con una calidad humana grandiosa, lo mejor que he tenido en el arte, un ser lleno de sueños y humanidad. Un quijote.

\section{ESCOPOLAMINA}

El borrachero, arbusto de América meridional, de la familia de las solanáceas que alcanza unos cuatro metros de altura, y bajo sus grandes y vellosas hojas y sus flores blancas de forma tubular y su fruto drupáceo, las gallinas entran en delirio con su grato y narcótico olor nocturno. En los seres humanos consumir su fruto causa estados alternos.

Pero a este vilipendiado arbusto, por culpa de la delincuencia, no se le ha permitido mostrar sus bellezas. Su flor, al igual que la de la amapola, se ha convertido en un estigma para la sociedad. Hablar del borrachero es hacer referencia a la escopolamina, droga usada por ladrones, especialmente en el altiplano cundiboyacense.

La flor se presenta en otra óptica, en otra perspectiva, con luces y brillos producto de la hojilla de oro; oro que representa lo incorruptible, lo noble y lo valioso. Como un sol irradia y en un torbellino transporta a los lugares que la imaginación pueda llevar. Caminos insondables, quizás oscuros, pero alternativa para construir unos referentes y nuevas miradas, acordes a nuestra contemporaneidad.

\section{A MODO DE CONCLUSIÓN}

El modelo usado por el postmodernismo antropológico nos ayuda a abordar ciertas preguntas en torno a la Historia del arte: ¿Somos partidarios de una concepción interpretativa de la disciplina? ¿Nos ha faltado conciencia en los modos de representación y de experimentar con ellos? ¿Podría incluirse la historia del arte en el género de la ficción? ¿Permite el modelo usado por la etnografía ser usado para la historia del arte, especialmente en la aplicación de la polifonía, la dialógica y la autoría dispersa?

La propuesta hace su trasegar en la Microhistoria, y en las reflexiones y presupuestos antropológicos de la llamada corriente posmoderna o contemporánea, puesto que el dialogo y la 
entrevista están enmarcados dentro de la etnografía era necesario hacer uso de las nuevas lecturas y proposiciones que al respecto la antropología me permitía tener a mano.

La síntesis y la claridad en las respuestas fue algo es algo que llama la atención y en especial la forma no explicativa del responder, lo que permite, reflexionar en torno a la necesidad de reconstruir contextos y ampliar los marcos de referencia, sobre los cuales tendríamos que movernos.

Partir de paradigma indiciario conllevó a dejar planteadas muchas puertas como potencial para que quien se acerque al documento pueda comprender desde su perspectiva personal la sociedad en la cual está inmerso. Ya lo afirma Ginzburg, la realidad es opaca; pero existen ciertos puntos privilegiados que nos permiten descifrarla. Continuando con esta idea, unas disciplinas como el psicoanálisis y el Trabajo Social que se basan en la hipótesis de que detalles aparentemente insignificantes pueden revelar fenómenos profundos y significativos, tendrían en este modelo alternativas para ampliar sus campos de acción e investigación, que les permitirán dar respuestas a necesidades y problemas no expresados en forma directa.

En el contexto del arte, las formas de saber tienden a ser mudas, y sus reglas formales no se prestan con facilidad a ser articuladas, ni aún a ser expresadas, por ello en este tipo de saber entran en juego factores que no pueden medirse como el sentido de la vista y la intuición. Ginzburg hace una distinción entre intuición alta y baja. La intuición baja que tiene sus raíces en los sentidos (aunque más allá de ellos), y no tiene nada que ver con la intuición extrasensorial, producto de los varios irracionalismos de los siglos diecinueve y veinte. Esta intuición existe en todo el mundo, sin salvedades geográficas, históricas, étnicas, de sexo o de clase; y esto significa que es muy diferente a toda forma de conocimiento "superior" restringido a una elite.

De forma similar a lo expuesto por Michael Taussig en su libro, se realizó una exploración a través de esta propuesta investigativa, la cual como un arte alternativo tiene mucho en común con el Dadaísmo, pues se torna en una propuesta _ arte que disloca, altera, un arte arriesgado y peligroso salido del alma humana, sensible a la exposición del juego del yo con el Otro, como producto histórico inconsciente, en el cual el lector tiene una enorme responsabilidad.

Como se ha visto a lo largo de la propuesta, ésta cuestiona muchas cosas y presupone muy pocas, por ello, el trabajo parte de las verdades de un ser y se involucran en el ser social de la verdad, no como una realidad de los hechos sino como una interpretación y representación de los mismos, tal vez libre de la historia que Walter Benjamín señala como el narcótico más poderoso y es la historia que cuenta "cómo realmente sucedieron las cosas".

Con el deseo de alterar la imaginería y los rituales académicos de carácter explicativo y sus promesas alquímicas de orden, se pueden usar e incorporar los principios de montaje, ensamble, mezcla e hipertexto que reflejan más las búsquedas del hombre contemporáneo al cual sus discusiones y comentarios le surgen más de su imposibilidad de pensar en términos académicos. 
La omisión de citas dentro delos textos desarrollados a partir del diálogo del maestro, se debe a primera instancia a un desacuerdo a estar constantemente saliendo del mundo al cual nos introduce la lectura, por ello es factible la posibilidad de conocer la información de antemano en forma de hipertexto, trascrito textualmente y con las referencias para profundizar en ellos, si el lector lo desea, más no como una razón de ser del texto.

La experiencia del ejercicio con las obras permitió tener acercamientos, encuentros y desencuentros con ellas, muchas veces ni imaginados. Esta circunstancia amplió la percepción, por el grado de complejidad e incluso simpleza en cosas que algunas de ellas fueron realizadas, planteadas o resueltas, y a su vez llevó a dejar al lado presupuestos conceptuales y teóricos que en muchos casos cohíben y coartan las miradas.

\section{BIBLIOGRAFÍA}

ANGEL , Felix, Nosotros, un trabajo sobre los artistas antioqueños. Medellín, Museo El Castillo, 1976

ARFUCH, Leonor, La entrevista, una invención dialógica, Ediciones Paidos Ibérica, Barcelona, 1995

AROSEMENA, Justo . Colección "Vivan los creadores". Medellín. Vol 11, Secretaria de Educación y Cultura de la Alcaldía de Medellín. 2002

ARTES, La revista, Vol 2 Julio -diciembre. Medellín, Facultad de Artes Universidad de Antioauia, 2005

BAJTíN, M.M, Estética de la creación verbal, Siglo veintiuno editores, Mexico, 1982

CALABRESE, O. Representación de la muerte y muerte de la representación. Ediciones Cátedra, Madrid, 1993

CARANTON, Josué, "Rodrigo Callejas, Historias de una vida. Un modelo teórico-metodológico". Tesis de maestría en Historia del Arte Universidad de Antioquia, Medellín, 2007

DUCROT, Oswald, Polifonía y argumentación, Universidad del Valle, Cali, 1988

ECO, Umberto y SEBEOK, Thomas, Eds. El signo de los tres, Dupin, Holmes y Peirce, Editorial Lumen, Barcelona, 1989

FABULA, Revista No 3, Bogotá, 2000

FOUCAULT, Michel. "Entrevista a Michel Foucault". 20 de enero de 1984. Conducida por Raúl Fornet-Betancourt, Helmut Becker y Alfredo Gómez-Müller. Entrevista publicada en el blog Dianoia Psicoanálisis. http://jingshenfengxi.blogspot.com/2009/11/entrevista-michelfoucault.html (Consultado el 24 de junio de 2013) 
GADAMER, Hans-Georg, Los caminos de Heidegger, Ed. Herder, Barcelona, 2002.

GINZBURG; Carlo, en Morelli, Freud y Sherlock Holmes: indicios y método científico, ECO, Umberto y SEBEOK, Thomas, Eds. El signo de los tres, Dupin, Holmes y Peirce, Editorial Lumen, Barcelona, 1989, Págs. 116 a 163

El queso y los gusanos. Barcelona: Muchnik. 1981

GIRALDO, Efren y PULGARÍN, Francisco, Proyecto para una revolución narrativa y otros ensayos críticos, Episteme Ediciones, Medellín 2004.

GOMBRICH, E.H., Los usos de las imágenes, Fondo de cultura económica, México, 2003.

HARDT, Michael, La sociedad mundial del control, en revista Euphorion, Número Especial Virtual, Medellín, 2005, recuperado en http://revistaeuphorion.wordpress.com/dossiers/ el 28 de junio de 2013.

HEIDEGGER, MARTIN, Versión española de Helena Cortés y Arturo Leyte en: Caminos de bosque, Madrid, Alianza, 1996.

MANGUEL, Alberto, Leyendo imágenes, Editorial Norma, Bogotá, 2002.

MASTROIANNI, Marcello. Sí, ya me acuerdo..., Memorias, Ediciones Grupo Zeta, Barcelona, 1997.

PODRO,Michael, Los historiadores del arte críticos, LA balsa de la Medusa, Madrid, 2001.

PINCHEIRA TORRES, Ivan, Grupo de Estudios en Historia de las Ciencias, GEHC (Editores). Control Social y Objetivación : escrituras y tránsitos de las Ciencias en Chile, Universidad de Chile, Santiago de Chile, 2012. 217 p.

RAMIREZ, Imelda, Una visita a la casa y la obra de EthelGilmour. Medellín. Universidad Nacional de Colombia. 1996

ROJO, Grinor. "Crítica Del Canon, Estudios Culturales, Estudios Postcoloniales y Estudios Latinoamericanos: Una Convivencia Difícil. http://www.buenastareas.com/ensayos/Cr\%C3\%ADtica-Del-Canon-Estudios-CulturalesEstudios/2797416.html (Consultado el 14 de mayo de 2013) 